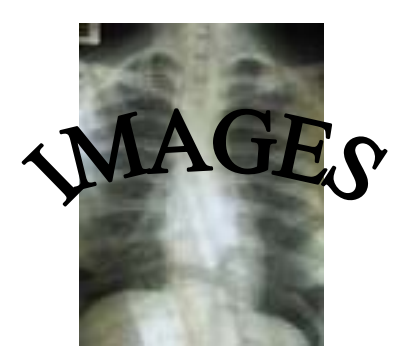

\title{
Endoscopy Ultrasound Imaging of an Abdominal Aortic Aneurysm
}

Karim R. Masri, M.D.

William J. Salyers, M.D.

University of Kansas School of Medicine-Wichita

Department of Internal Medicine

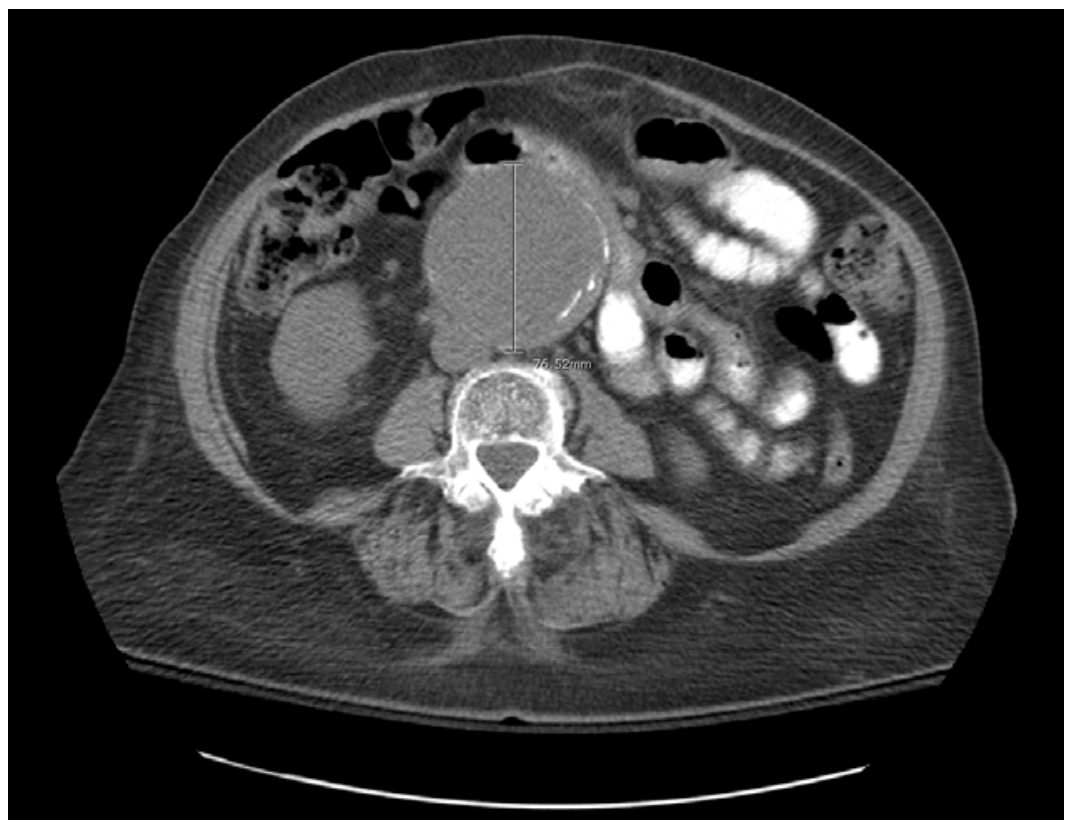

Figure 1. Computed tomography (CT) of an abdominal aortic aneurysm.

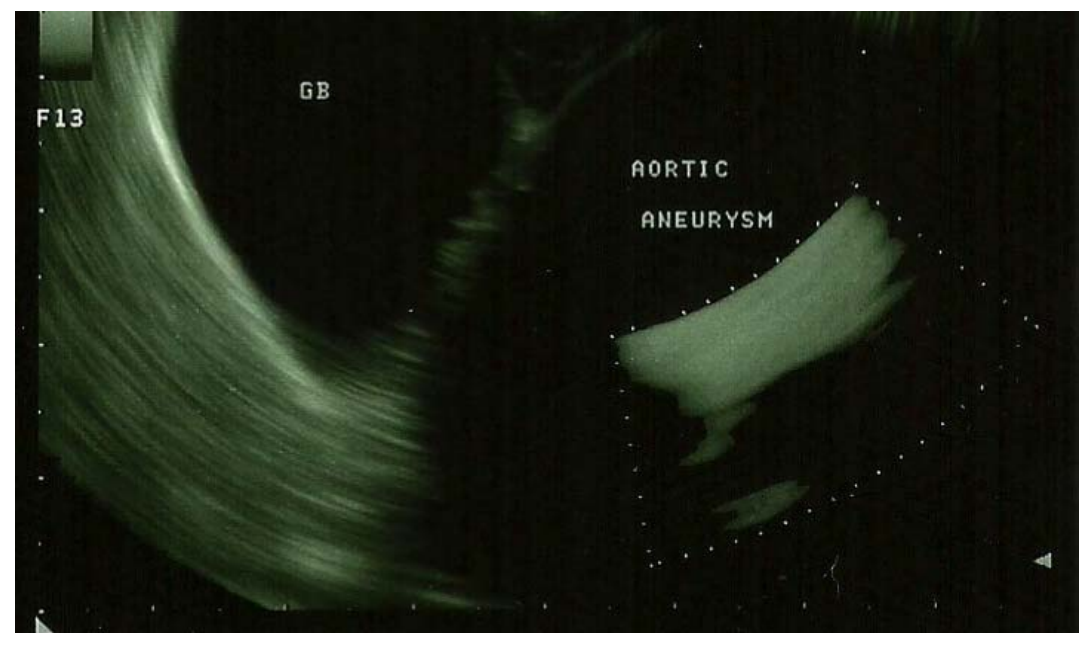

Figure 2. Endoscopic ultrasound (EUS) image of the patient's gall bladder and abdominal aortic aneurysm. Doppler is seen in right-side of image. 
An 89-year-old white female presented with abnormal liver function tests and jaundice in a cholestatic pattern. CT revealed a large fusiform unruptured infrarenal abdominal aortic aneurysm (AAA) measuring $7.4 \mathrm{~cm}$ in maximal dimension (Figure 1) with no biliary splenic or pancreatic abnormalities. An ultrasound (US) of the liver showed mild common bile duct (CBD) dilation, up to $8 \mathrm{~mm}$, with an ill-defined hypoechoic lesion measuring $1.4 \mathrm{x} 1.9 \times 0.7 \mathrm{~cm}$ on the pancreatic head not seen on CT. Magnetic resonance cholangiopancreatography (MRCP), completed after the US, showed no definite obstructive lesions in the vicinity of the liver or pancreas. The CBD was $7 \mathrm{~mm}$ and the AAA was noted.

Carbohydrate antigen (CA) 19-9 was elevated at $181 \mathrm{U} / \mathrm{mL}(<55 \mathrm{U} / \mathrm{mL})$ while cytomegalovirus, herpes simplex virus, viral hepatitis, ceruloplasmin, anti-nuclear antibody, anti-mitochondrial antibody, anti-smooth muscle antibody were normal. CA $19-9$ is a nonspecific tumor marker associated clinically in patients with suspected pancreatic malignancies, in particular intraductal papillary mucinous neoplasia.

In light of the US and CA-19-9 findings, the patient underwent EUS examination of the pancreas. A large cystic appearing lesion was seen on EUS near the duodenal bulb in the region of the head of the pancreas and measured $7.4 \mathrm{~cm}$. Doppler ultrasound confirmed the area was vascular consistent with the known AAA. No parenchymal abnormalities were identified. Figure 2 shows a section of the patient's gallbladder in relation to her AAA. Images of an AAA relative to the gallbladder are uncommon in the literature.

EUS is an innovative tool in the field of diagnostic gastroenterology. It has combined the potential of CT imaging by layering pathology in situ and staging neoplasms. EUS identifies pancreatic lesions suggestive of malignancies. EUS findings representing malignancy include: 1) main pancreatic duct greater than or equal to $7 \mathrm{~mm}$, 2) irregular and thick walled cystic lesion greater than $30 \mathrm{~mm}$, and 3) mural nodules greater than $10 \mathrm{~mm}$. Fine need aspiration is done to identify cystic lesions in combination with tumor markers. ${ }^{1-4}$

AAAs readily have been identified during EUS procedures. Varadarajulu et al. ${ }^{5}$ reported that out of 413 patients suspected of pancreatic-cystic lesions, four were aneurysms. Although AAAs are mostly infrarenal due to atherosclerosis buildup, ${ }^{6}$ they are not the most common kind of abdominal aneurysms. Splenic artery aneurysms are more prevalent. ${ }^{7}$

\section{References}

${ }^{1}$ Cellier C, Cuillerier E, Palazzo L, et al. Intraductal papillary and mucinous tumors of the pancreas: accuracy of preoperative computed tomography, endoscopic retrograde pancreatography and endoscopic ultrasonography, and long-term outcome in a large surgical series. Gastrointest Endosc 1998; 47(1):42-49. PMID: 9468422.

2 Sugiyama M, Atomi Y, Saito M. Intraductal papillary tumors of the pancreas: evaluation with endoscopic ultrasonography. Gastrointest Endosc 1998; 48(2):164-171. PMID: 9717782.

${ }^{3}$ Pais SA, Attasaranya S, Leblanc JK, Sherman S, Schmidt CM, DeWitt J. Role of endoscopic ultrasound in the diagnosis of intraductal papillary mucinous neoplasms: correlation with surgical histopathology. Clin Gastroenterol Hepatol 2007; 5(4):489-495. PMID: 17350894.

${ }^{4}$ Tanno S, Nakano Y, Nishikawa T, et al. Natural history of branch duct intraductal papillarymucinous neoplasms of the pancreas without mural nodules: long-term follow-up results. Gut 2008; 57(3):339-343. PMID: 17660227.

${ }^{5}$ Varadarajulu S, Eloubeidi MA. Diagnosis of an aneurysm masquerading as a pancreatic-cyst lesion at EUS. Gastrointest Endosc 2007; 65(4):721-725. PMID: 17327129. 
${ }^{6}$ Wanhainen A, Björck M, Boman K, Rutegård J, Bergqvist D. Influence of diagnostic criteria on the prevalence of abdominal aortic aneurysm. J Vasc Surg 2001; 34(2):229-235. PMID: 11496273.

7 Trastek VF, Pairolero PC, Joyce JW, Hollier LH, Bernatz PE. Splenic artery aneurysms. Surgery 1982; 91(6):694-699. PMID: 7079972.

Keywords: endosonography, abdominal aortic aneurysm, case report 